\title{
Numerical Simulation Research on the Stability of Urban Underground Interchange Tunnel Group
}

\author{
Shiding Cao $\mathbb{D}$, ${ }^{1,2}$ Shusen Huo $\mathbb{D},{ }^{3,4}$ Aipeng Guo $\mathbb{D}^{3,4}$ Ke Qin $\mathbb{D}^{3,}{ }^{3,4}$ Yongli Xie, \\ and Zhigang Meng ${ }^{3,4}$ \\ ${ }^{1}$ Shenzhen Transportation Design \& Research Institute Co., Ltd., Shenzhen 518003, China \\ ${ }^{2}$ Key Laboratory of Mine Geological Hazards Mechanism and Control, Xian 710054, China \\ ${ }^{3}$ School of Mechanics and Civil Engineering, China University of Mining \& Technology (Beijing), Beijing 100083, China \\ ${ }^{4}$ State Key Laboratory for Geomechanics and Deep Underground Engineering, \\ China University of Mining \& Technology (Beijing), Beijing 100083, China
}

Correspondence should be addressed to Shusen Huo; 782826845@qq.com and Aipeng Guo; guoaipeng0422@163.com

Received 5 March 2021; Revised 3 April 2021; Accepted 16 April 2021; Published 29 April 2021

Academic Editor: Gan Feng

Copyright (c) 2021 Shiding Cao et al. This is an open access article distributed under the Creative Commons Attribution License, which permits unrestricted use, distribution, and reproduction in any medium, provided the original work is properly cited.

\begin{abstract}
Highway tunnel group has the characteristics of large span and small spacing, and the load distribution characteristics of surrounding rock between each tunnel section are complex. Based on geological prospecting data and numerical analysis software, the stress distribution characteristics along the characteristic section and the profile of the tunnel group were obtained. Taking Shenzhen Nanlong complex interchange tunnel group project as an example, the results show that (1) the excavation area of Qiaocheng main tunnel gradient section is large, and the grade of surrounding rock is poor, which leads to the phenomenon of large-area stress concentration on the right wall of this section. (2) The tunnels in the joint construction section of the tunnel group belong to the stress concentration area, and the influence of the right line excavation of Qiaocheng on the stability of the main tunnel of the right line of Baopeng is greater than that of the main tunnel of the left line of Baopeng. (3) The stress concentration of surrounding rock in the intersection section between the main tunnel and the ramp is caused by the too small distance between the main tunnel and the ramp of Baopeng. (4) The distance between the partitions in the K3+240 multiarch section of Qiaocheng is an important factor affecting the stability of the surrounding rock of the cave.
\end{abstract}

\section{Introduction}

In recent years, with the continuous acceleration of urbanization in my country, the scale of urban rail transit network has increased sharply, and the proportion of urban underground traffic has increased. Among them, urban underground expressways can effectively alleviate urban ground traffic congestion without occupying the urban surface. Among them, urban underground expressway is a transportation infrastructure which can effectively alleviate urban ground traffic congestion, does not occupy urban ground construction land, is beneficial to urban environmental protection, and has completely feasible engineering technology and national defense function. Numerical simulation methods based on computer technology can more comprehensively consider various factors affecting the stress of surrounding rock during tunnel excavation so as to simulate the process of tunnel excavation more realistically. Numerical simulation is more and more widely used in the simulation of tunnel excavation process and analysis and study of surrounding rock stress.

Many scholars at home and abroad have conducted a large number of studies on tunnels with complex geological conditions through 3D simulation software. NgocAnhDoden and colleagues used FLAC3D finite difference code to conduct numerical studies, which made it possible to use full three-dimensional simulation to predict the impact between tunnels. In the full three-dimensional simulation, most of the elements of the mechanized tunneling process have been modeled [1]. Zhu et al. used physical model 
experiments and different numerical simulation software such as FLAC3D, FPC, and 3DEC to study the safety mining depth of the antidip bedding slope and the failure mechanism of the excavated slope [2-5]. Li et al. based on the fully coupled hydraulic mechanics model, numerical simulation and analysis of the boundary conditions of the rock constant normal stiffness were carried out [6]. Wang et al. used servo control GCTS 2000 rock mechanics system combined with test X-ray computed tomography (CT) scan to study the fracture evolution and energy characteristics of rock mass under fatigue cyclic loading [7]. Meng et al. used numerical simulation software to model heterogeneous materials with complex microstructures, which has broad application prospects in the field of mechanical properties analysis of heterogeneous materials [8]. Qu et al. and colleagues used a three-dimensional finite element numerical simulation method to study the mechanical behavior of the primary lining structure for the large cross-sectional tunnels of Gongti North Road Station of Beijing Metro Line 10 [9, 10]. Zhang et al. and colleagues used Changsha Rail Transit 3. The construction of the shield tunnel of the line number line adjacent to the large-section mining method tunnel is the engineering support. Aiming at the muddy siltstone formation, the FLAC3D numerical simulation and model test are used to study the influence law of the shield tunnel adjacent to the mining method tunnel construction, and based on the surface settlement, the criterion proposes the impact zoning [11]. Bai et al. applied FLAC3D computing software to Suzhou Street Station of Beijing Metro Line 10, which is a complex station with large difference in stratum mechanical properties, to optimize the excavation construction scheme, simulate the dynamic construction process, and analyze the deformation and ground settlement of soil around the underground excavation station in each construction step [12]. Yu et al. and colleagues based on the Songshan Lake tunnel underpassing the building section of the Guanhui Intercity Railway, through FLAC3D numerical simulation analysis, obtained the deformation law of the tunnel surrounding rock, And on this basis, the influence of tunnel excavation on the deformation of surface buildings is analyzed [13]. Wang et al. relied on the Hongling Middle Road-Laojie-Shaibu Section of Shenzhen Metro Line 3 to study the overlapping tunnel project and established a FLAC3D three-dimensional simulation method that can fully reflect the entire process of shield tunneling [14]. Zhang et al. took the short-distance overlap tunnel shield construction of the Pudongnan Road Station-Nanpu Bridge Station interval of the Shanghai Rail Transit Pearl Line Phase II Project as the research object. The stress and deformation of the old tunnel lining caused by the shield construction of the tunnel were simulated [15]. Huang and Zhang used the FLAC3D nonlinear large-deformation program to numerically simulate the three-dimensional deformation law of the ground caused by the four-step bench method construction of the overlapped tunnel by using the FLAC3D nonlinear large-deformation program [16]. Zhang et al. took the largespan, small-spacing Foyangling tunnel construction of Binlai Expressway as an example and analyzed the mechanical mechanism of large-span and small-spacing highway tunnel construction through field monitoring data comparison verification and FLAC3D numerical simulation analysis. The fast Lagrangian analysis of the continuum is used in the three-dimensional numerical simulation software to eliminate the stress and strain of the tunnel and surrounding rock $[17,18]$.

The construction environment of the Nanlong compound interchange tunnel group is complicated, and it is a rare complex large-span subway tunnel project in China. In order to ensure the smooth progress of the project, the finite difference software FLAC3D was used to model the tunnel group in a proportional manner, and the stress concentration value and the stress concentration influence range of each characteristic section of the tunnel group were calibrated, and the stability of the surrounding rock of each characteristic section of the tunnel group was carried out. The analysis provides references for numerical modeling of highway tunnel groups with similar engineering backgrounds.

\section{Distributed Sensing}

The Shenzhen Nanlong Composite Overpass Tunnel Group starts from Fulong Road in the north and connects with Baopeng Passage and the north extension of Shahe East Road. It runs in the north-south and east-west directions. The 4 main tunnels are connected by 4 ramps. The spatial position relationship is shown in Figure 1. As shown, the length of the Qiaocheng main tunnel is $1100 \mathrm{~m}$, the distance between the left and right lines is $43 \mathrm{~m}$, the buried depth is $65 \mathrm{~m}$ to $71 \mathrm{~m}$, the excavation width of the standard section is $16 \mathrm{~m}$, the expressway standard is adopted, the main line has 6 lanes in both directions, and the design speed is $60-80 \mathrm{~km} /$ $\mathrm{h}$. The whole section is located in four types of stratum: plain fill, moderately weathered granite, soil blocky granite, and slightly weathered granite; $\mathrm{K} 3+100$ to $\mathrm{K} 3+500$ are largespan transition sections, with a maximum excavation span of $32 \mathrm{~m}$ and a height of $19.2 \mathrm{~m}$. The largest section of tunnel excavation in the world. The Baopeng main tunnel is $1300 \mathrm{~m}$ long, the distance between the left and right lines is $45 \mathrm{~m}$, and the buried depth is $70 \mathrm{~m}$ to $90 \mathrm{~m}$. The excavation width is the same as that of the Qiaocheng main tunnel. The design speed is $60 \sim 80 \mathrm{~km} / \mathrm{h}$, with $6 \sim 8$ lanes in both directions. In the granite formation, the excavation span of the 4 ramps is $7 \mathrm{~m}$ and the height is $7.8 \mathrm{~m}$. The whole section of the tunnel group adopts the mining method.

\section{Numerical Calculation Model Construction}

\subsection{Numerical Model Size and Boundary Conditions.} Based on the geological exploration data and considering the size effect of the tunnel excavation, the finite difference software FLAC3D is used to model the tunnel group and the local layer. The left and right boundaries of the Qiaocheng main tunnel are calculated to be $450 \mathrm{~m}$, and the bottom boundary of the tunnel to the lower boundary of the model is $120 \mathrm{~m}$. Baopeng tunnel deflection is $\angle 15^{\circ}$ from north to south in the section $\mathrm{K} 0+650$ to $\mathrm{K} 1+100$. The left and right boundary of the model in the section $\mathrm{K} 0+650$ to $\mathrm{K} 1+100$ 


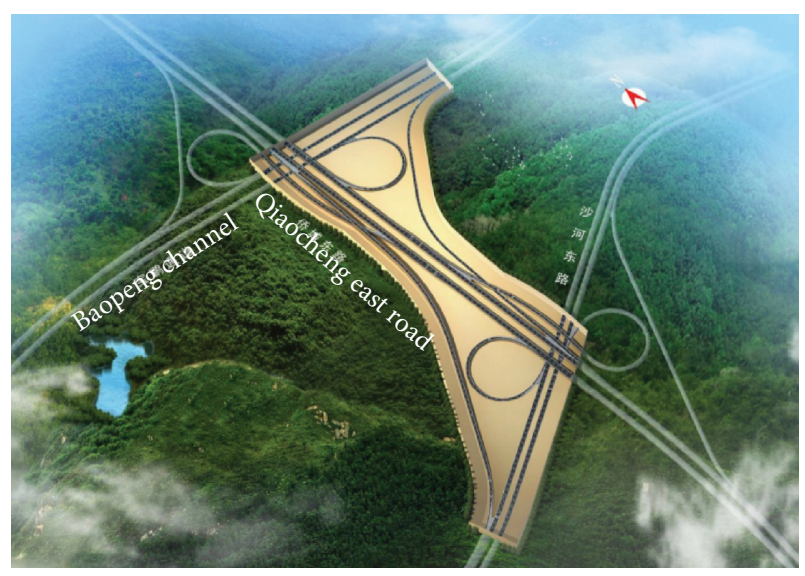

FIgURE 1: Nanlong compound interchange tunnel group.

are $550 \mathrm{~m}$, the left boundary of the model in the section $\mathrm{K} 1+100$ to $\mathrm{K} 1+500$ is $250 \mathrm{~m}$, the right boundary is $850 \mathrm{~m}$, and from the bottom of Baopeng main tunnel, the lower boundary of the model is $130 \mathrm{~m}$, as shown in Figure 2. The stratum is divided into plain fill, moderately weathered granite, soil block granite, and slightly weathered granite from top to bottom. The Mohr-Coulomb elastoplastic constitutive model that characterizes the shear failure of rock and soil is selected [11]. The physical and mechanical calculation parameters of each layer are shown in the Table 1. As shown in1, the calculation model size is as follows: length $\times$ width $\times$ height $=1281 \mathrm{~m} \times 1105 \mathrm{~m} \times 198 \mathrm{~m}, \quad$ as shown in Figure 3. The normal direction displacement conditions of the front, back, left, right, and bottom of the model are set to rigid constraints, and the top of the model is set to a free surface. The model is modeled with a hexahedral mesh, which is divided into 3.5 million elements and 530000 nodes.

3.2. Analysis of the In Situ Stress Field before Excavation. As shown in Figure 4, the tectonic stress field of the original formation is evenly distributed, there is no obvious stress concentration area, and the vertical stress uniformly increases along the depth of the formation. The vertical stress range of the formation is 0 26 MPa, and the larger stress area is located at the bottom of the model, which is far away from Baopeng. At about $110 \mathrm{~m}$ from the bottom of the tunnel, the maximum in situ stress is $26.48 \mathrm{MPa}$. The original ground stress along the tunnel is $1.2 \sim 1.8 \mathrm{MPa}$, which is evenly distributed along the stratum.

The main tunnel of Qiaocheng is mostly located in plain fill. The Baopeng line is mostly located at the junction of moderately weathered granite and slightly weathered granite. The tectonic stress of the fill layer is lower than other geological layers, and the original tectonic stress along the Baopeng line is slightly higher, along the Overseas Chinese Town.

\section{Analysis of Numerical Simulation Results}

The numerical analysis software FLAC3D is used to solve the tunnel excavation program and simulate the one-off

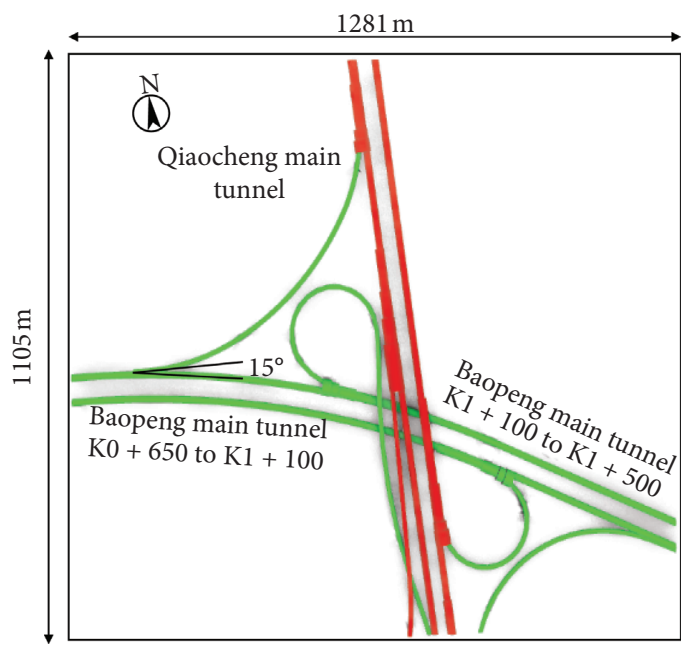

Figure 2: Numerical model of tunnel group.

excavation of tunnel group. The analysis results of the stress field, stress concentration area, and stress concentration length along the tunnel surrounding rock are shown in Table 2.

\subsection{Analysis of the Stress Field along the Long-Span Transition} Section. The mileage of the Qiaocheng transition section is $\mathrm{K} 3+350$ to $\mathrm{K} 3+600$, which is located on the right line of the Qiaocheng main tunnel, as shown in Figure 5. The left- and right-side walls of the tunnel are located in three strata, whose cross-section excavation length is large. The top of the tunnel is located in the plain soil, and the bottom of the tunnel is located in the breezed granite bottom. As shown in Figure 6(a), the stress concentration value of surrounding rock of the tunnel vault and invert is lower than the left- and right-side walls, the stress concentration value of the leftand right-side walls of the tunnel is $12 \mathrm{MPa}$, and the stress concentration value of the vault is $1 \mathrm{MPa}$. As shown in Figure 6(b), the distance between the large-span transition section and the right tunnel is $24 \mathrm{~m}$, and the distance from the left ramp is $7 \mathrm{~m}$. Under the condition of one-time excavation of the simulated tunnel, the distance between the transition section and the ramp is less than that of the right side. The distance between chambers, ramp excavation has higher disturbance on the left-side wall of the long-span section than on the right, the stress concentration value of the left-side wall of the tunnel is $12 \mathrm{MPa}$, which is much higher than the stress concentration value of the right-side wall of $6 \mathrm{MPa}$, and the influence length along the left-side wall of the transition section is $134 \mathrm{~m}$ and the height is $13 \mathrm{~m}$, as shown in Figure 6(c).

\subsection{Analysis of Stress Field along the Co-Construction Section} of the Tunnel Group. The joint construction section of the tunnel group is shown in Figure 7. The distance to the main tunnel of Qiaocheng is $40 \mathrm{~m}$, the distance to the main tunnel of Baopeng is $45 \mathrm{~m}$, and the distance between the roof and floor of the upper and lower tunnels is $5 \mathrm{~m}$. As shown in Figure 8(a), the main tunnel in the joint construction section 
TABLE 1: Stratum parameters.

\begin{tabular}{|c|c|c|c|c|c|c|}
\hline Strata & $\begin{array}{c}\text { Elastic modulus } \\
(\mathrm{GPa})\end{array}$ & $\begin{array}{l}\text { Poisson's } \\
\text { ratio }\end{array}$ & $\begin{array}{l}\text { Tensile strength } \\
(\mathrm{MPa})\end{array}$ & $\begin{array}{c}\text { Cohesion } \\
(\mathrm{MPa})\end{array}$ & $\begin{array}{c}\text { Internal friction } \\
\text { angle }\left(^{\circ}\right)\end{array}$ & $\begin{array}{c}\text { Density }(\mathrm{Kg} / \\
\left.\mathrm{m}^{3}\right)\end{array}$ \\
\hline Plain fill & 0.3 & 0.27 & 0.025 & 0.25 & 28 & 1950 \\
\hline $\begin{array}{l}\text { Moderately weathered } \\
\text { granite }\end{array}$ & 0.6 & 0.25 & 0.05 & 0.5 & 31 & 2050 \\
\hline Lumpy granite & 5 & 0.20 & 2 & 2 & 42 & 2200 \\
\hline $\begin{array}{l}\text { Slightly weathered } \\
\text { granite }\end{array}$ & 25 & 0.17 & 10 & 10 & 55 & 2300 \\
\hline
\end{tabular}

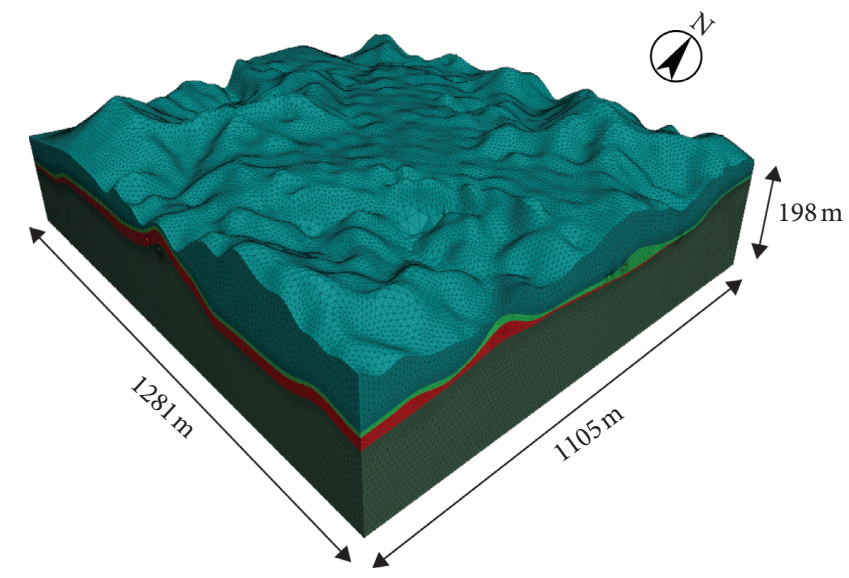

Figure 3: Stratum model of Qiaocheng-Baopeng tunnel group.

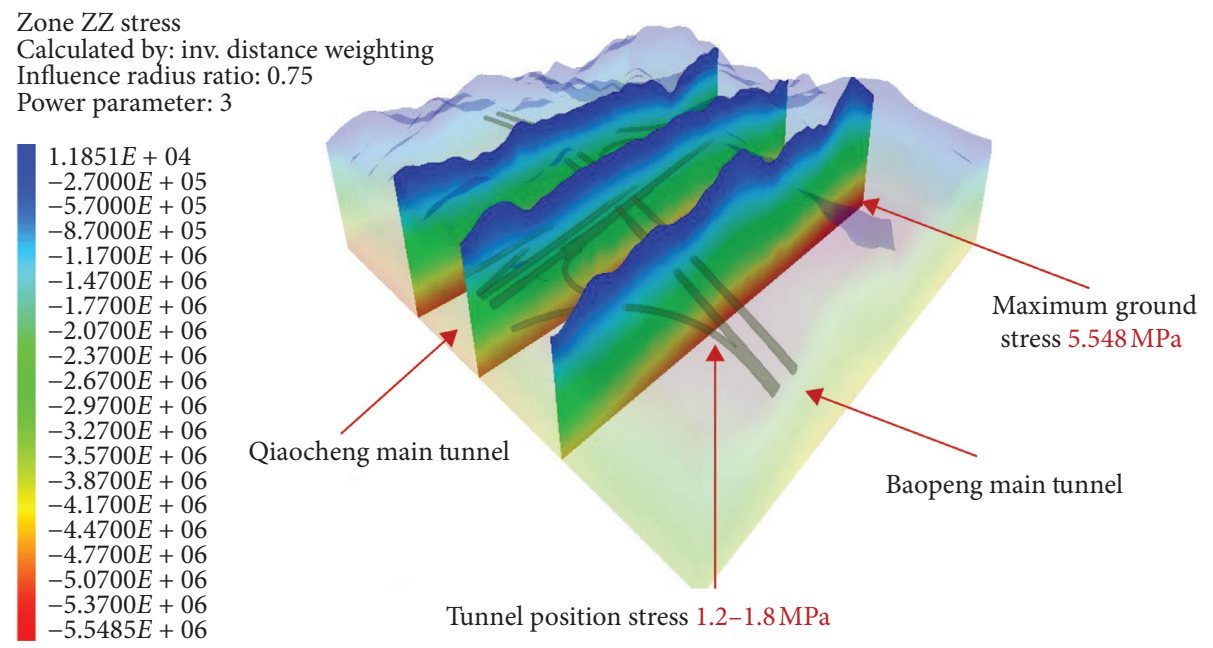

Figure 4: Section of the original in situ stress field.

of Qiaocheng is located in the strata of weathered granite, massive Fenghua granite and breezed granite, and the surrounding rock is of poor grade. Therefore, the vertical stress concentration value of the main tunnel on the right line of Qiaocheng is $8 \mathrm{MPa}$ to $10 \mathrm{MPa}$, which is higher than that of Baopeng main tunnel. The stress peak is located at mileage $\mathrm{K} 3+760$. As shown in Figure $8(\mathrm{~b})$, the Baopeng line in this section is located in a kind of stratum, and the vertical stress along the line concentrates with a length of $75 \mathrm{~m}$ and a height of $5 \mathrm{~m}$.

4.3. Stress Field Analysis of Intersection of Qiaocheng Right Line and Baopeng Ramp. The mile number of the intersection section of the right ramp of Qiaocheng and Baopeng is $\mathrm{K} 0+840$ to $\mathrm{K} 1+20$, and the two ramps 
TABLE 2: Stress concentration of tunnel in characteristic area.

\begin{tabular}{lcccc}
\hline $\begin{array}{l}\text { The serial } \\
\text { number }\end{array}$ & Type & $\begin{array}{c}\text { Vertical stress } \\
\text { concentration value }(\mathrm{MPa})\end{array}$ & $\begin{array}{c}\text { Length } \\
(\mathrm{m})\end{array}$ & The lithology \\
\hline 1 & Qiaocheng gap-K3+100-320 & $4 \sim 6$ & 30 & $\begin{array}{c}\text { Breezy granite } \\
\text { Medium weathering/block } \\
\text { weathering/breezy }\end{array}$ \\
2 & Qiaocheng gradient section-K3+100-500 & $9 \sim 12$ & 134 & The weathering \\
3 & Qiaocheng-Baopeng joint construction & $8 \sim 10$ & 448 & Moderate weathering/breezing \\
4 & section-K3 + 580-920 & $5.2 \sim 7.4$ & 72.9 & Moderate weathering/breezing \\
5 & Qiaocheng left line gap-K3+860-K4+50 & $10.5 \sim 22.3$ & 9.9 & Moderate weathering \\
6 & Qiaocheng right line and Baopeng ramp & $1.8 \sim 2.4$ & 536 & Moderate weathering/lump \\
7 & Baopeng right line gap-K18+580-780 & $4.9 \sim 9.7$ & 94.3 & weathering/slight weathering \\
8 & Baopeng right line gap-K19+120-920 & $1.9 \sim 3.2$ & 594 & Plain fill \\
\hline
\end{tabular}

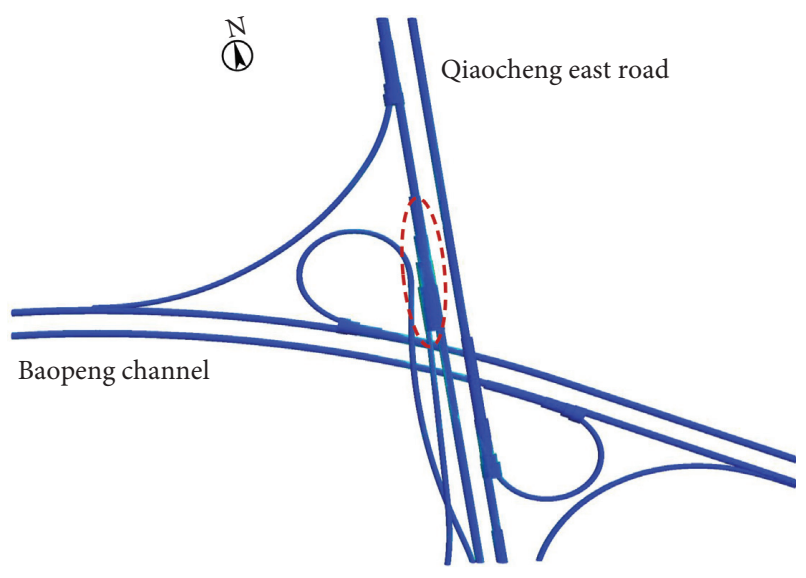

(a)

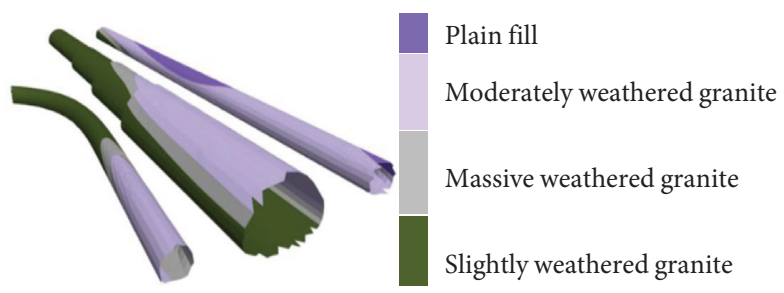

(b)

Figure 5: Intercept location map of transition section K3 + 350 to 600 in Qiaocheng. (a) Location map. (b) Stratigraphic map of location.
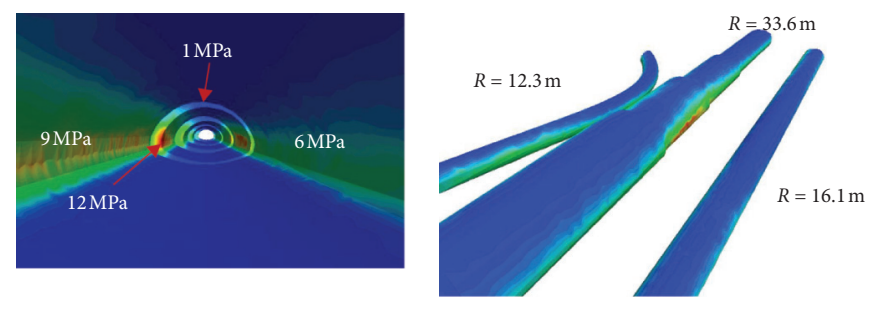

(a)

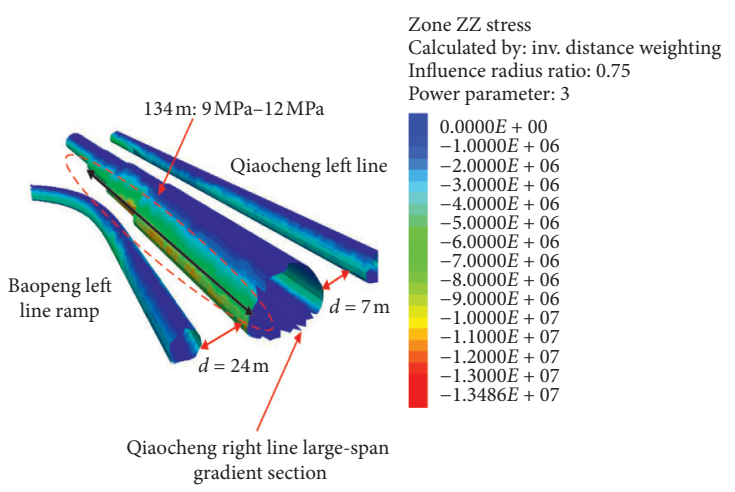

(c)

FIgURE 6: Vertical stress nephogram from K3+350 to 600 in transition section of Qiaocheng. (a) Inside. (b) Right view. (c) Left view.

intersect at $\mathrm{K} 0+920$, as shown in Figure 9. This section is located in the breezed granite stratum, and the stress concentration values of the surrounding rocks of the vault and invert of the two ramps are slightly lower than those of the left- and right-side walls. As shown in Figure 10, the width of the ramp is $7.47 \mathrm{~m}$, and the vertical stress concentration value increases from the two ramps to the middle. As shown in Figure 10(a), the vertical stress concentration ranges from 10.5 to $22.3 \mathrm{MPa}$, and the peak value of $22.3 \mathrm{MPa}$ is reached in the tunnel at the intersection of $\mathrm{K} 0+920$. As shown in Figure $10(\mathrm{~b})$, the radius of the ramp on the right line of Qiaocheng is $14.8 \mathrm{~m}$ larger 


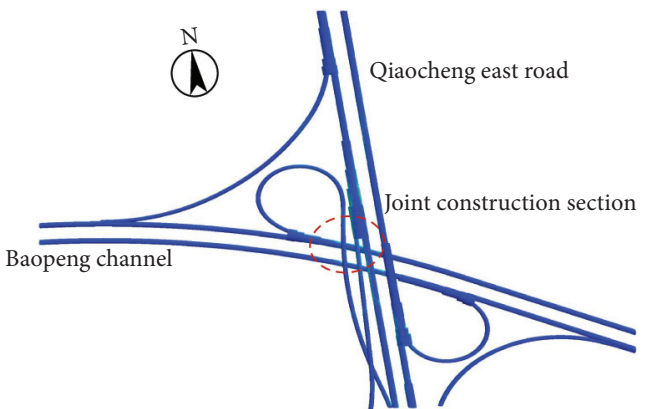

(a)

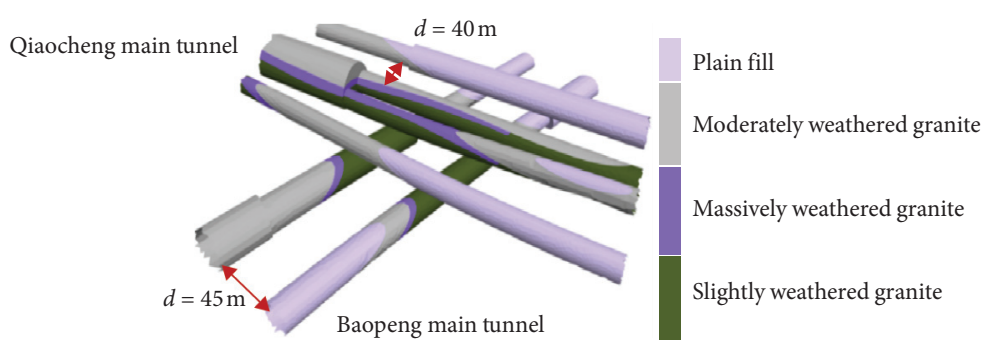

(b)

FIGURE 7: Intercept location map of K3 + 580 to 920 of Qiaocheng-Baopeng co-construction section. (a) Location map. (b) Stratigraphic map of location.

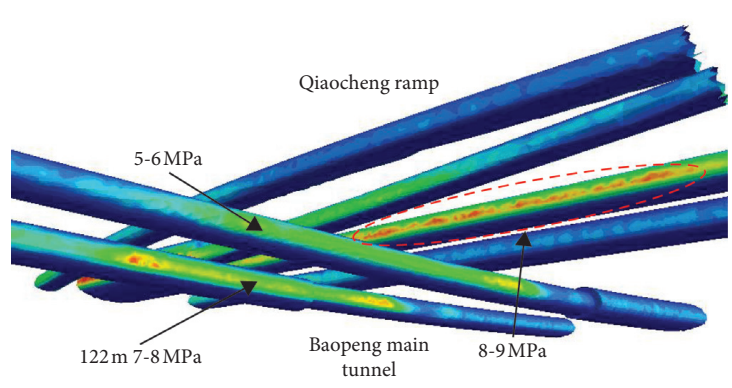

(a)

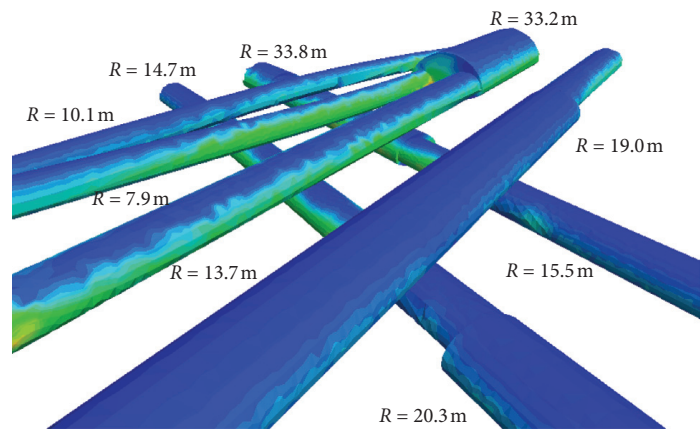

(b)

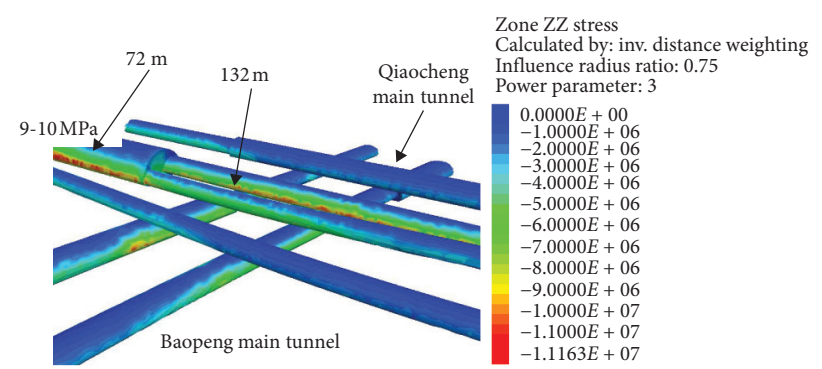

(c)

Figure 8: Vertical stress nephogram from K3 + 580 to 920 of Qiaocheng-Baopeng joint construction section. (a) Bottom view. (b) Top view. (c) Front view.

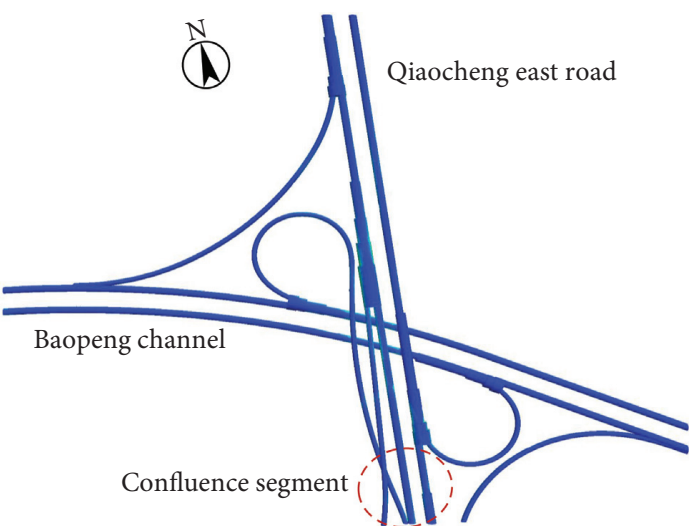

(a)

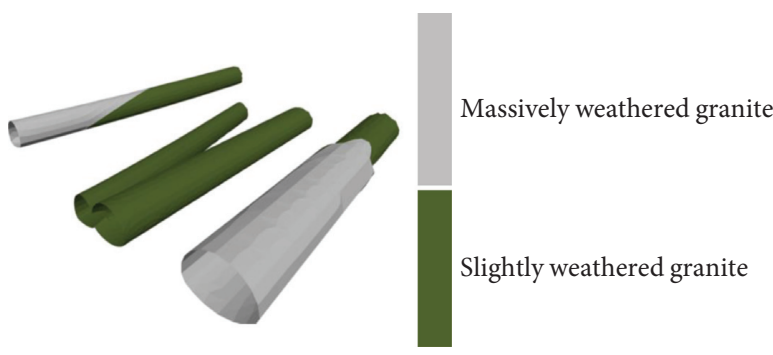

(b)

Figure 9: Interception location map from $\mathrm{K} 0+840$ to $\mathrm{K} 1+20$ at the interchange of the right line of Qiaocheng and Baopeng ramp. (a) Location map. (b) Stratigraphic map of location. 


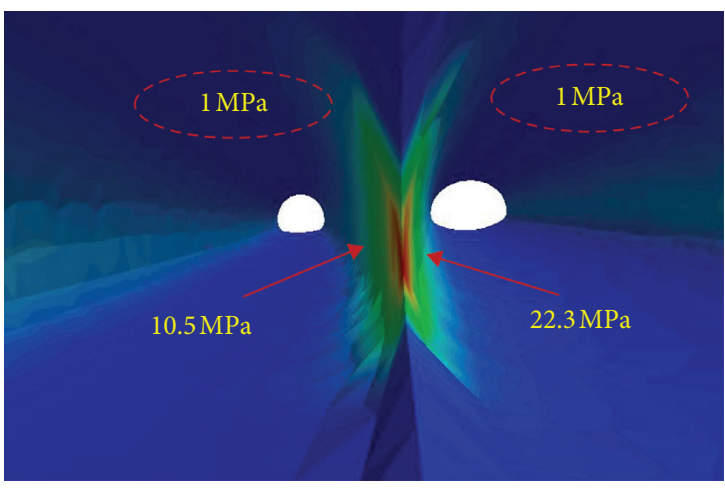

(a)

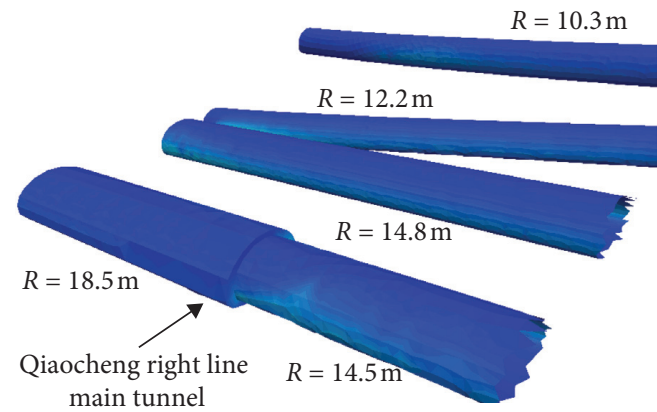

(b)

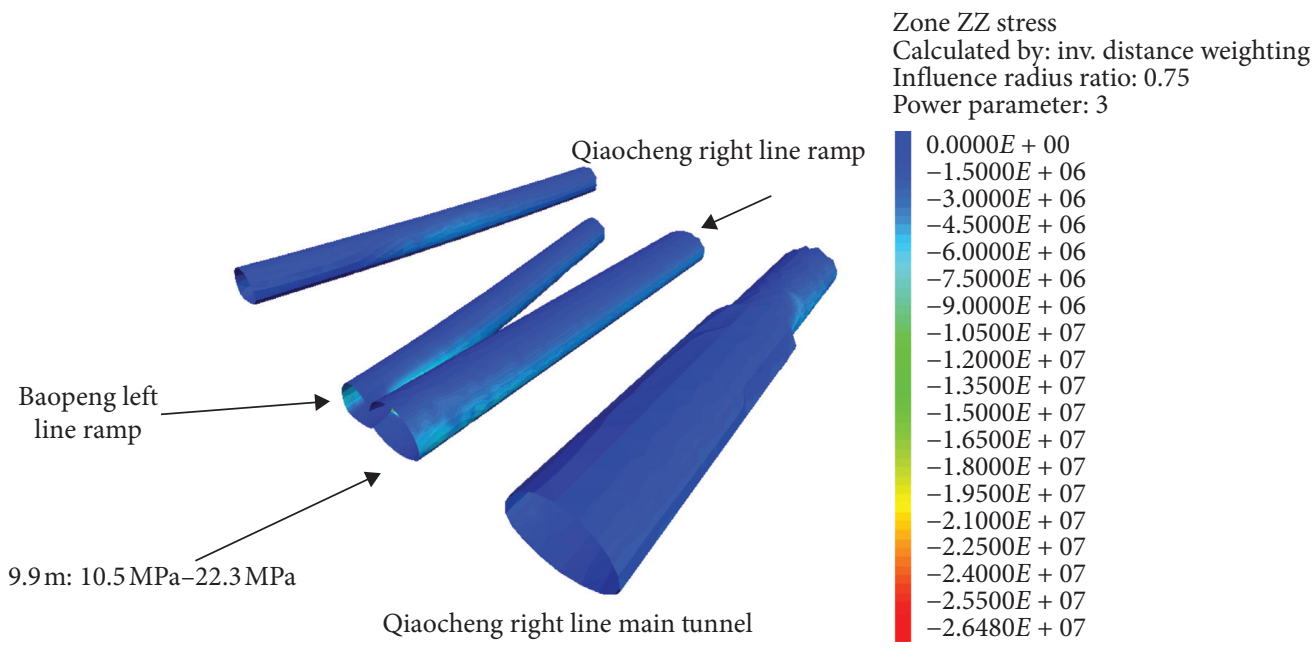

(c)

Figure 10: Vertical stress cloud map from $\mathrm{K} 0+840$ to $\mathrm{K} 1+20$ at the intersection of the right line of Qiaocheng and Baopeng ramp. (a) Internal. (b) Right view. (c) Left view.

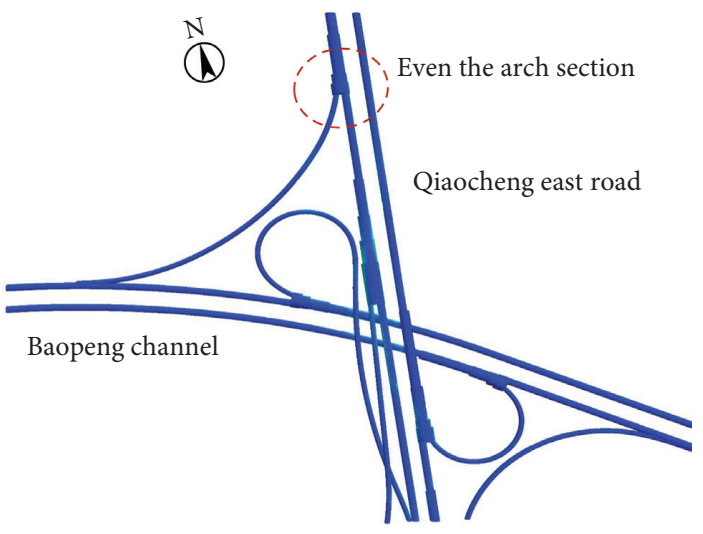

(a)

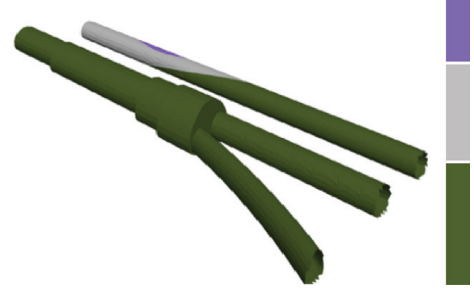

Moderately weathered granite

Massively weathered granite

Slightly weathered granite

(b)

FIgURE 11: Interception location map of gap K3 + 100-320 in Qiaocheng. (a) Location map. (b) Stratigraphic map of location.

than that of Baopeng, $12.2 \mathrm{~m}$. Therefore, the location of the peak is closer to the right line of Qiaocheng. The stress concentration length along the ramp of the right line of Qiaocheng is $9.9 \mathrm{~m}$.
4.4. Analysis of Stress Field along Qiaocheng Arch Section. As shown in Figure 11, the tunnel at section K3 + 100-320 of Niubi, Qiaocheng, is located in the bottom layer of breezed granite. The tunnel radius of the double-arch section is 


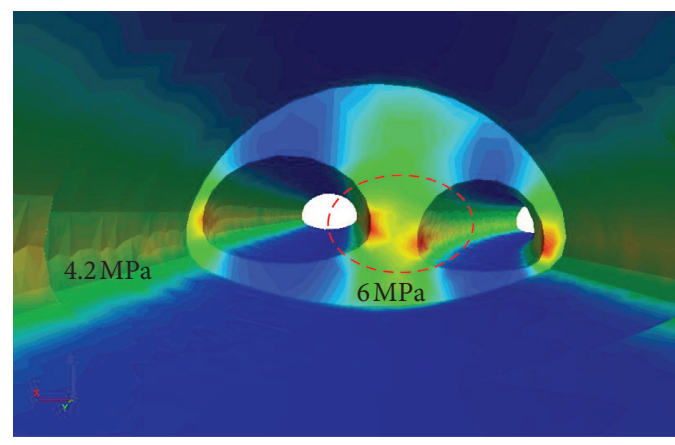

(a)

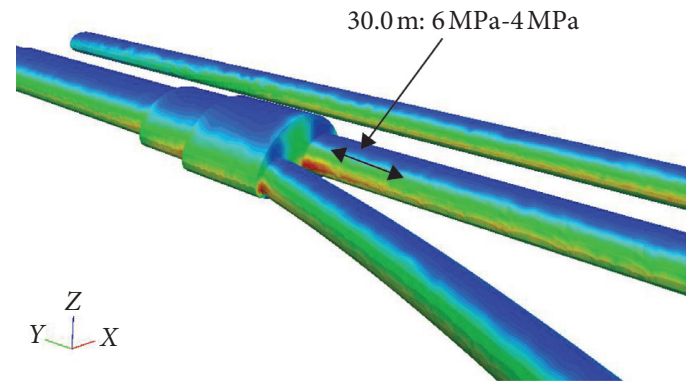

(b)

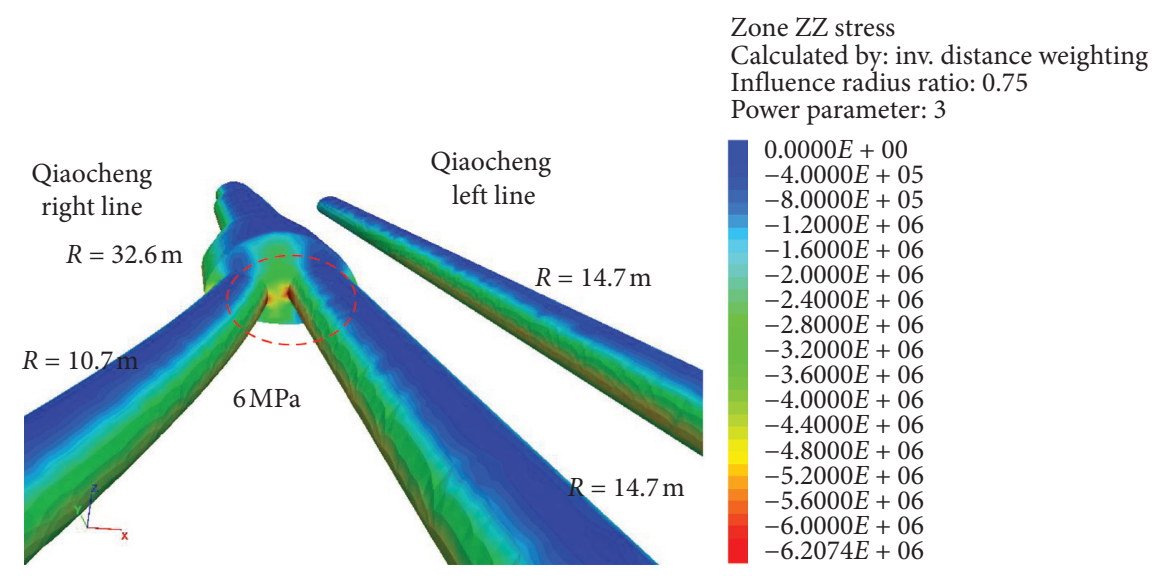

(c)

FIGURE 12: Stress nephogram of Niunose K3 + 100-320 in Qiaocheng. (a) Internal. (b) Left view. (c) Right view.

$32.6 \mathrm{~m}$, the tunnel radius of the left and right lines is $10.7 \mathrm{~m}$ and $14.7 \mathrm{~m}$, respectively, and the length of the double-arch section is $6 \mathrm{~m}$, as shown in Figure 12(a). The stress concentration values of the surrounding rocks of the two tunnels along the left and right lines and the side walls of the Great Arch section are higher than those of the tunnel vault and the invert section. The vertical stress concentration values range from 4 to $6 \mathrm{MPa}$ and the stress concentration length is $30 \mathrm{~m}$, among which the stress concentration value of the left wall of the Great Arch section is $4.2 \mathrm{MPa}$. In the tunnel, the stress field is concentrated, with the maximum stress of $6 \mathrm{MPa}$, concentrated at the middle partition wall, as shown in Figure 12(b).

\section{Numerical Model Feature Profile Analysis}

Based on the vertical stress field analysis along the tunnel, the positions of stress concentration values along the tunnel were calibrated for profile analysis. The characteristic profile analysis results of each tunnel section are shown in Table 3.

\subsection{Analysis of Profile Stress Field in Long-Span Gradient} Section. Based on the stress field analysis along the gradient section, it is believed that the ramp excavation has the greatest influence on the stability of the surrounding rock on the left side of the tunnel. The nearest point between the long-span gradient section and the ramp is $\mathrm{K} 3+600$, and the characteristic profile is made along the tunnel lateral with the nearest point as the center, as shown in Figure 13.

The stress concentration value on the right wall of the gradient section is $5 \mathrm{MPa}$ to $9.5 \mathrm{MPa}$, with an impact depth of $6 \mathrm{~m}$ and a height of $7.5 \mathrm{~m}$, as shown in Figure 13. There is no stress concentration area in the rock mass between the transition section and the right tunnel, which indicates that the excavation of the right tunnel will not have a significant impact on the stability of the surrounding rock in the long-span section. The stress concentration on the right-side wall of the gradient section is due to its location in soil block granite and slightly weathered stratum, which leads to low strength of surrounding rock and poor bearing capacity. As shown in Figure 14, the stress concentration value of the left wall of the long-span section ranges from 3.7 $\mathrm{MPa}$ to $8.2 \mathrm{MPa}$, with an impact depth of $7 \mathrm{~m}$ and a height of $8 \mathrm{~m}$, and it is connected with the stress affected area on the left ramp. According to the analysis of the stress influence range of the left- and right-side walls of the ramp, the stress influence range of the right side of the ramp is much larger than that of the left side, which indicates that the stress concentration phenomenon of the left wall in the longspan gradual change section is caused by the strong disturbance of the rock mass between the tunnels caused by the excavation of the ramp.

5.2. Analysis of Section Stress Field in the Joint Construction Section. In section $\mathrm{K} 3+760$ of the tunnel group, the main tunnels of Qiaocheng and Baopeng were built at the same time. 
TABLE 3: Analysis of sectional diagram simulation results.

\begin{tabular}{|c|c|c|c|}
\hline $\begin{array}{l}\text { The serial } \\
\text { number }\end{array}$ & Position & $\begin{array}{l}\text { Concentration value } \\
(\mathrm{MPa})\end{array}$ & The lithology \\
\hline 1 & Baopeng gap-K19+600 & 1.5 & Plain fill \\
\hline 2 & Baopeng ramp-K0+700 & 2.7 & Plain fill/moderately weathered granite \\
\hline 3 & Baopeng gap-K19+480 & $2.3 \sim 3$ & Plain fill \\
\hline 4 & $\begin{array}{l}\text { Qiaocheng-Baopeng ramp } \\
\text { interchange-K0+920 }\end{array}$ & 23.8 & Slightly weathered granite \\
\hline 5 & $\begin{array}{l}\text { Qiaocheng-Baopeng tunnel } \\
\text { group-K3 }+760\end{array}$ & $8 \sim 10$ & $\begin{array}{l}\text { Plain fill/moderately weathered granite /massive } \\
\text { weathered granite/slightly weathered granite }\end{array}$ \\
\hline 6 & $\begin{array}{l}\text { Qiaocheng long-span J4 gradient } \\
\text { section -K } 3+560\end{array}$ & $8 \sim 9$ & $\begin{array}{l}\text { Plain fill/moderately weathered granite /massive } \\
\text { weathered granite/slightly weathered granite }\end{array}$ \\
\hline 7 & Baopeng gap $-\mathrm{K} 19+000$ & $2.3 \sim 2.4$ & Plain fill \\
\hline 8 & Baopeng gap-K18+720 & $2 \sim 3$ & Plain fill \\
\hline 9 & Qiaocheng gap-K3 +240 & $4.5 \sim 5.6$ & Slightly weathered granite \\
\hline
\end{tabular}

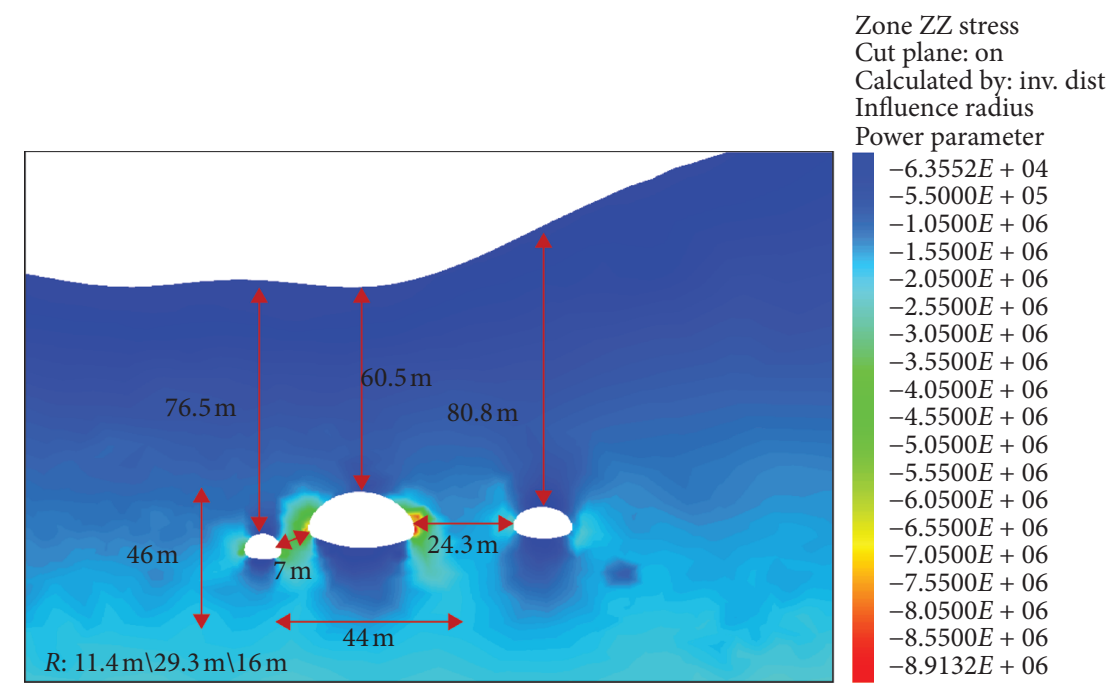

FIGURE 13: Map of the spatial position of tunnel in section K3 + 560 of J4 gradient section of Qiaocheng.

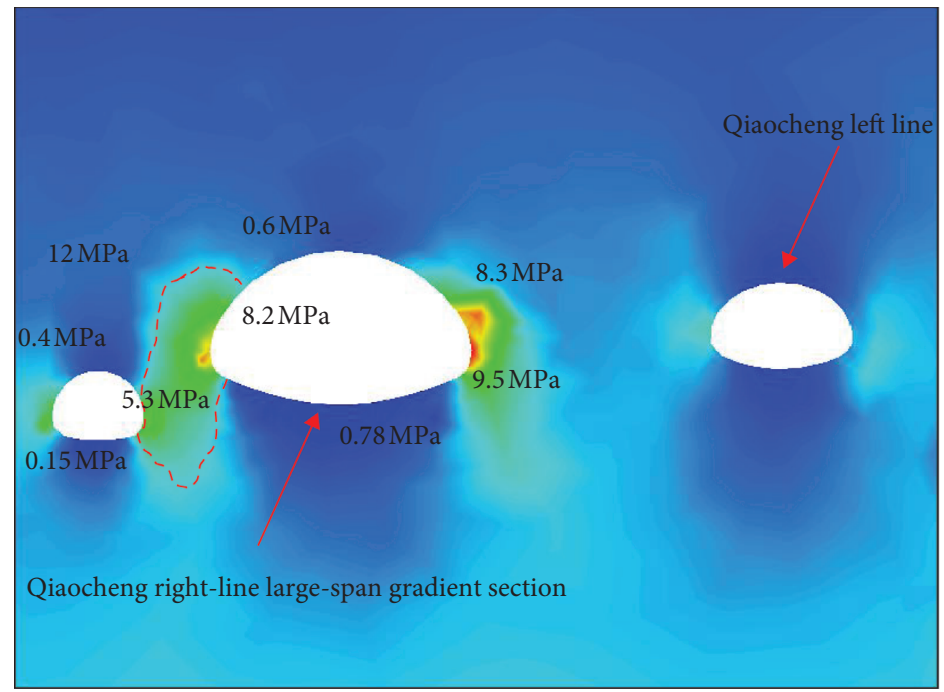

Zone ZZ stress Cut plane: on

Calculated by: inv. dist

Influence radius

Power parameter

$-6.3552 E+04$

$-5.5000 E+05$

$-1.0500 E+06$

$-1.5500 E+06$

$-2.0500 E+06$

$-2.5500 E+06$

$-3.0500 E+06$

$-3.5500 E+06$

$-4.0500 E+06$

$-4.5500 E+06$

$-5.0500 E+06$

$-5.5500 E+06$

$-6.0500 E+06$

$-6.5500 E+06$

$-7.0500 E+06$

$-7.5500 E+06$

$-8.0500 E+06$

$-8.5500 E+06$

$-8.9132 E+06$

FIGURE 14: Stress cloud diagram of K3 +560 in the long-span J4 gradient section of Qiaocheng. 


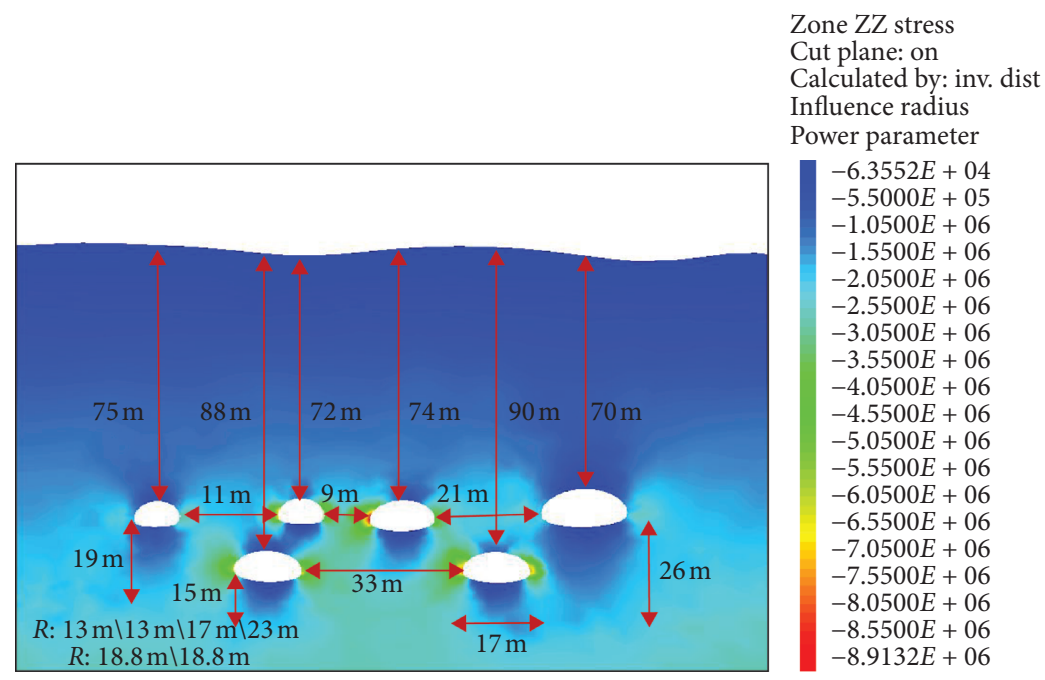

Figure 15: Spatial position relation diagram of section tunnel of Qiaocheng-Baopeng joint construction section.

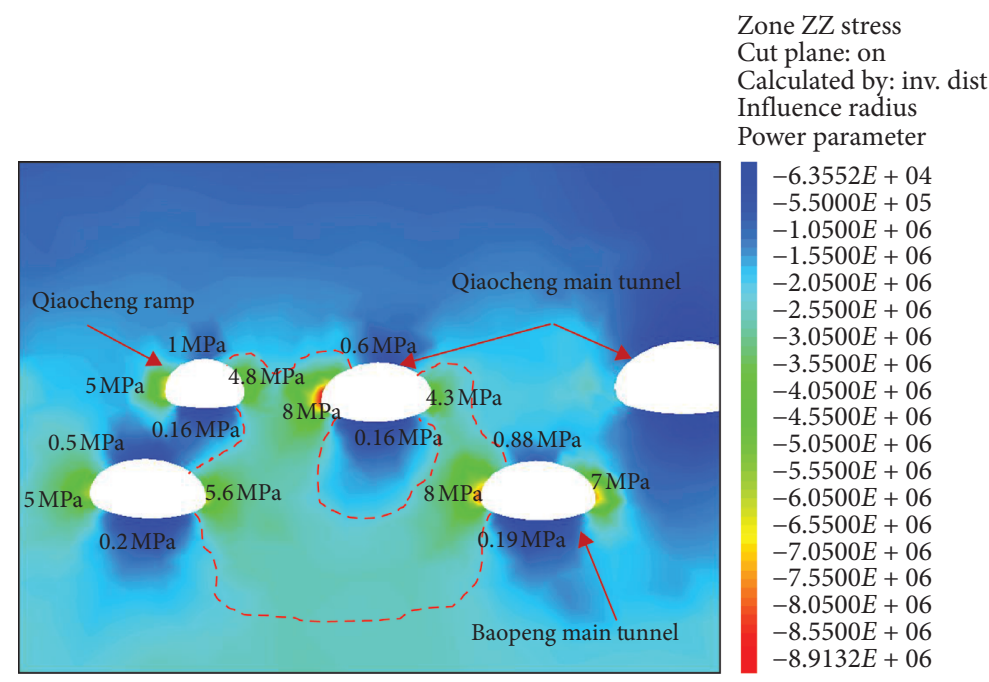

FIGURE 16: Stress nephogram of tunnel group K3 +76 jointly built by Qiaocheng and Baopeng (part).

The spatial position relationship of each tunnel is shown in Figure 15. The main tunnel of Qiaocheng left line is located in the plain land reclamation layer, and the tunnel excavation did not produce strong disturbance to the surrounding rock of the chamber, and the main tunnel of Qiaocheng left line did not produce stress concentration. Lines to overseas Chinese town at the right around the ramp are less than the distance to the double-hole diameter. There are 4 tunnels between the rock mass in large area of stress concentration phenomenon, $8 \mathrm{MPa}$ to $4.8 \mathrm{MPa}$ to stress concentration values, including: (1) Overseas Chinese town right line main tunnel hence meets the ramp respectively in three kinds of formation, the tunnel between the bearing capacity of surrounding rock is weak, leading to line the main tunnel right; then, the left ramp excavation wall stress concentration occurred at $8 \mathrm{MPa}$. (2) The main tunnel on the right side of Qiaocheng and the main tunnels on the left and right sides of Baopeng are all in the same stratum, and their surrounding rock mechanical properties are the same. The stress sharing ratio between the surrounding rock of Baopeng left and right line due to the excavation of Qiaocheng tunnel is solved, after balance calculation, the stress bearing of the rock between Qiaocheng and the left side of Baopeng is 0.85 times that of the right side, as shown in Figure 16. Baopeng right line stress concentration value is $8 \mathrm{MPa}$, the stress concentration value of the left Baopeng line is $6.5 \mathrm{MPa}$, which is 0.7 times that of the right line, basically in line with the calculation model. It shows that the excavation of Qiaocheng right line in the joint construction section has more influence on the stability of the main tunnel of Baopeng right line than on the main tunnel of Baopeng left line. (3) The stress-affected zones between the coconstruction section chambers are connected to each other, so it is suggested to adjust the co-construction section location or adopt the method of strengthening support to improve the overall stability of the tunnel group.

5.3. Analysis of Profile Stress Field at the Intersection of the Right Line of Qiaocheng and Baopeng Ramp. As shown in Figure 17, the section is located at $\mathrm{K} 0+920$ at the 


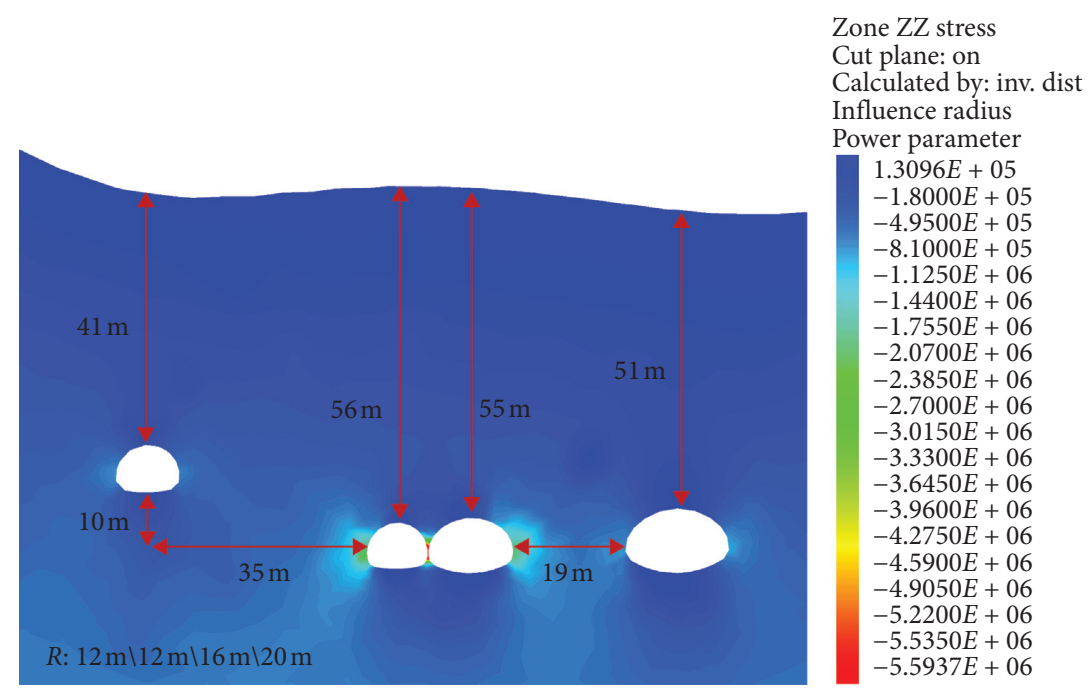

FIGURE 17: Spatial position map of the $0+920$ section tunnel in Qiaocheng.

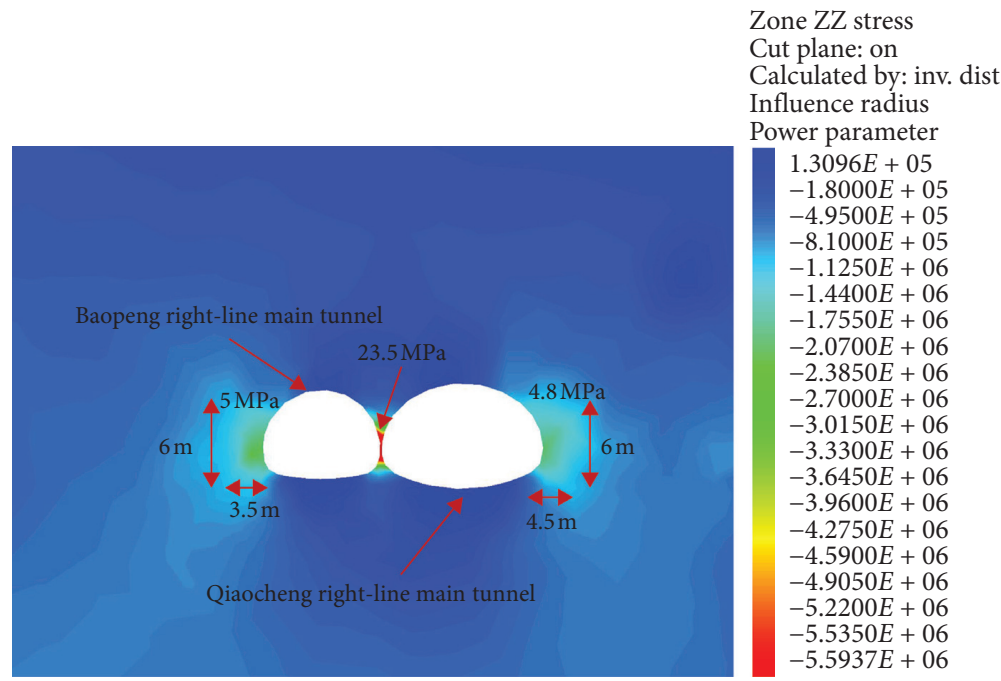

Figure 18: Qiaocheng 0+920 stress cloud map (local).

intersection of the main tunnel on the right line of Qiaocheng and Baopeng ramp. This section of tunnel is located in the breezed granite stratum, and the excavation of the left and right chambers in the intersection section has no influence on the stability of surrounding rock. The distance between the main tunnel of Qiaocheng and the left- and right-side walls of Baopeng ramp is too small, resulting in the stress concentration phenomenon in the middle surrounding rock, as shown in Figure 18. The peak stress is $23.5 \mathrm{MPa}$, and the influence height is $6 \mathrm{~m}$. The influence depth of the right wall and the left wall of the ramp of Qiaocheng main tunnel are $4.5 \mathrm{~m}$ and $3.5 \mathrm{~m}$, respectively, and the influence height is $6 \mathrm{~m}$. The vertical stress value of the surrounding rock is $4.8-5 \mathrm{MPa}$, and the distance between the two caves is $0.6 \mathrm{~m}$. In order to prevent the surrounding rock from being disturbed and unstable by the excavation of the near tunnel, it is suggested to strengthen the side wall support.
5.4. Analysis of Cross-Sectional Stress Field of Qiaocheng Multiarch Section. The section is located in the $\mathrm{K} 3+240$ multiarch section of Qiaocheng, as shown in Figure 19. The designed width of the middle partition is $6 \mathrm{~m}$. Under the simulated one-time excavation condition, the vertical stress of the middle partition wall of the multiarch between the main tunnel and the ramp is $2.1 \mathrm{MPa}-5.6 \mathrm{MPa}$, the influence width is $6 \mathrm{~m}$, and the height is $25 \mathrm{~m}$, as shown in Figure 20. The stress value higher ramp area is located in the middle of ZhuSui wall on the left and the right central wall; stress values were $5.6 \mathrm{MPa}$ and $5.4 \mathrm{MPa}$, because even the arch section of weathered granite strata in the breeze, stratum lithology, the vertical stress concentration will affect the stability of middle wall rock needed for sample analysis of rock mass, to do judgment.

The width of vertical stress of surrounding rock on the right wall of the main tunnel and the left wall of the ramp is $7 \mathrm{~m}$ and the height is $25 \mathrm{~m}$, which is roughly the same as the 


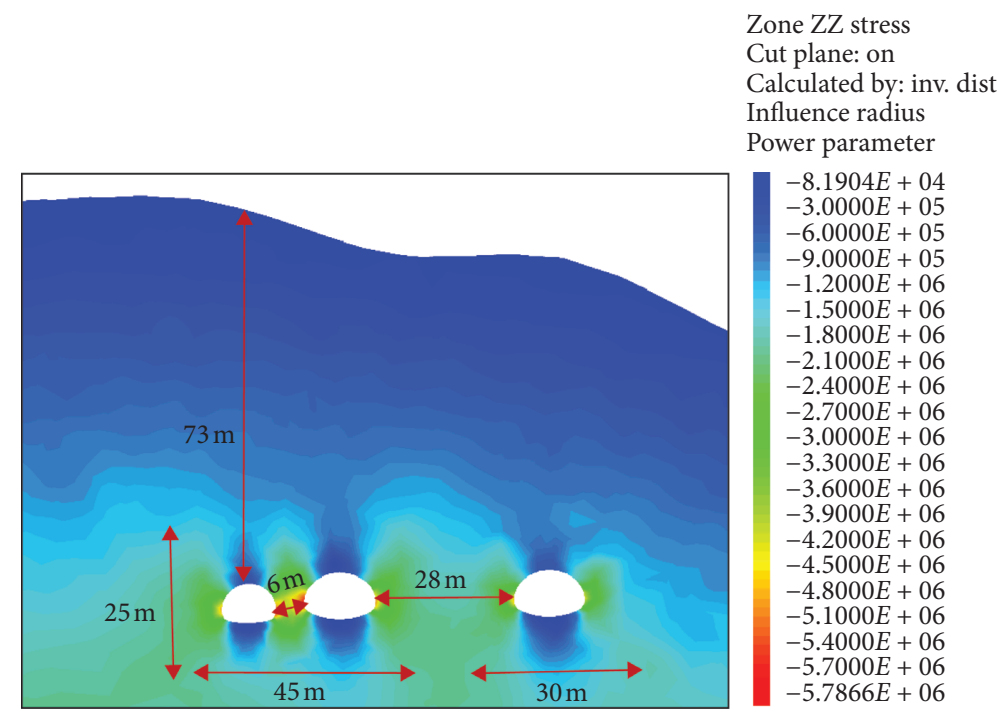

FIgURE 19: Stress nephogram of K3 + 240 ox nose section in Qiaocheng City.
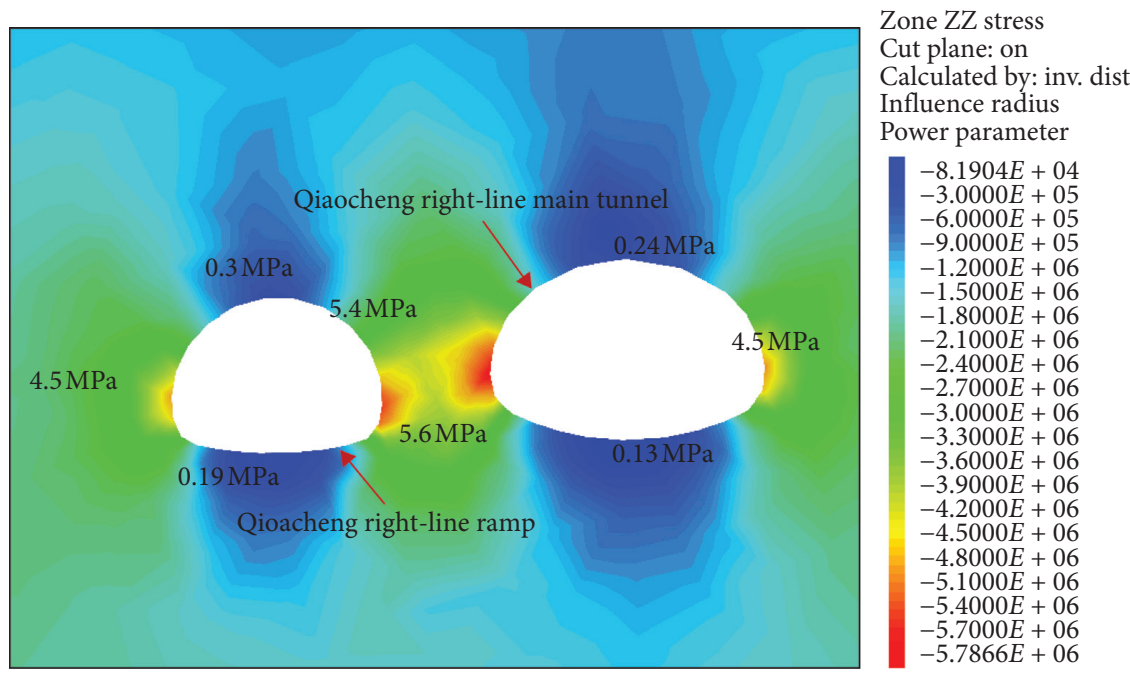

Figure 20: Stress nephogram of K3 + 240 ox nose section in Qiaocheng City (local).

influence range of the middle partition wall. The distance between the main tunnel and the ramp is small, and the stability of surrounding rock adjacent to the chamber is disturbed due to tunnel excavation, so the stress concentration of the middle partition wall of the multiarch is higher than that of the left- and right-side walls.

\section{Conclusions}

The stress field analysis results of each characteristic section of the tunnel group are as follows:

(1) The excavation of the adjacent ramp on the left side of Qiaocheng long-span gradual change section of the tunnel group affects the stability of surrounding rock between tunnels, resulting in the stress concentration of the rock mass on the left wall. The surrounding rock mass on the right side wall of the tunnel is located in different strata, and its own bearing capacity is poor.

(2) The stability of surrounding rock between the main tunnel on the right line of Qiaocheng and the ramp is poor. The distance between the tunnels is less than 1 times that of the tunnel, resulting in the stress concentration value of $8 \mathrm{MPa}$ in the surrounding rock between the tunnels. The stress ratio of surrounding rock of the main tunnel of Qiaocheng right line and the main tunnel of Baopeng left and right lines is unevenly distributed, and the stress of the rock between the right and left lines of Qiaocheng is 0.85 times that of the right line of Baopeng.

(3) Excavation of the right and left chambers at the intersection of the right line of Qiaocheng and Baopeng ramp has no effect on the stability of surrounding rock. The stress concentration of 
surrounding rock in the middle of the intersection section is caused by the small distance between the main tunnel of Qiaocheng and the left- and rightside walls of Baopeng ramp.

(4) The vertical stress concentration in the $\mathrm{K} 3+240$ multiarch section of Qiaocheng mainly occurs at the middle partition wall and the maximum excavation diameter of two tunnels, and the stress concentration value is $5.6 \mathrm{MPa}$. It is considered that the width of the middle partition is an important factor to determine the stability of the surrounding rock.

\section{Data Availability}

The data used to support the findings of this study are included within the article.

\section{Conflicts of Interest}

The authors declare that they have no conflicts of interest.

\section{Acknowledgments}

The authors gratefully acknowledge the financial support provided by the Key Special Project of the National Natural Science Foundation of China (no. 41941018), Key Laboratory of Mine Geological Hazards Mechanism and Control (no. KF2019-02), and Funding for the Special Survey Project of the Geological Environment of Typical Limestone Mines in Weibei (no. 20180205).

\section{References}

[1] N.-A. Do, D. Dias, and P. Oreste, "3D numerical investigation of mechanized twin tunnels in soft ground - influence of lagging distance between two tunnel faces," Engineering Structures, vol. 109, pp. 117-125, 2016.

[2] Z. Tao, C. Zhu, M. He, and M. Karakus, "A physical modelingbased study on the control mechanisms of Negative Poisson's ratio anchor cable on the stratified toppling deformation of anti-inclined slopes," International Journal of Rock Mechanics and Mining Sciences, vol. 138, Article ID 104632, 2021.

[3] C. Zhu, M. He, M. Karakus, X. Zhang, and Z. Tao, "Numerical simulations of the failure process of anaclinal slope physical model and control mechanism of negative Poisson's ratio cable," Bulletin of Engineering Geology and the Environment, vol. 80, no. 4, pp. 3365-3380, 2021.

[4] Z. G. Tao, C. Zhu, M. He et al., "Research on the safe mining depth of anti-dip bedding slope in Changshanhao Mine," Geomechanics and Geophysics for Geo-Energy and GeoResources, vol. 6, no. 2, pp. 1-20, 2020.

[5] C. Zhu, M. C. He, Q. Yin et al., "Numerical simulation of rockfalls colliding with a gravel cushion with varying thicknesses and particle sizes," Geomechanics and Geophysics for Geo-Energy and Geo-Resources, vol. 7, no. 1, pp. 1-15, 2021.

[6] B. Li, R. Bao, Y. Wang et al., "Permeability evolution of twodimensional fracture networks during shear under constant normal stiffness boundary conditions," Rock Mechanics and Rock Engineering, vol. 54, no. 3, pp. 1-20, 2021.

[7] Y. Wang, W. K. Feng, R. L. Hu et al., "Fracture evolution and energy characteristics during marble failure under triaxial fatigue cyclic and confining pressure unloading (FC-CPU) conditions," Rock Mechanics and Rock Engineering, vol. 54, pp. 1-20, 2020.

[8] Q. X. Meng, W. Y. Xu, H. L. Wang et al., "DigiSim-an open source software package for heterogeneous material modeling based on digital image processing," Advances in Engineering Software, vol. 146, no. 9, p. 16, 2020.

[9] W. B. Qu, X. R. Liu, Y. Fu et al., "Numerical simulation of preliminary lining of large section crossing tunnels constructed with PBA method," Rock and Soil Mechanics, vol. 30, no. 09, pp. 2799-2804, 2009.

[10] W. N. Qu, X. R. Liu, R. J. Huang et al., "Analysis on deformation monitoring and control of shallow buried large-span tunnel with piles," Civil Architectural and Environmental Engineering, vol. 31, no. 01, pp. 38-43, 2009.

[11] J. Zhang, L. Ye, C. Yan, B. Yan, P. Wei, and J. Feng, "Study on construction influence of shield tunnel of urban rail transit on large-section mining tunnel," Advances in Civil Engineering, vol. 2020, Article ID 6836492, 20 pages, 2020.

[12] M. Z. Bai, G. Duan, and A. J. Zhang, "Stability analysis of surrounding rock soil considering the variation of water content in unsaturated coagley soil," Journal of Engineering Geology, vol. 05, pp. 603-608, 2006.

[13] H. L. Yu, Q. L. Zhao, and S. R. Guo, "Research on influence of tunnel construction in shallow mine method on surface buildings," Railway Standard Design, vol. 59, no. 08, pp. 144-149, 2015.

[14] N. X. Wang, X. J. Zhang, M. Z. Gou et al., "Study on design and construction scheme optimization of large section double double," Arch Tunnel in Soft Ground Rock and Soil Mechanics, vol. 33, no. 01, pp. 273-279, 2012, in Chinese.

[15] H. B. Zhang, Z. Z. Yin, and J. G. Zhu, "Numerical simulation of the effect of shield construction of short-distance overlapping tunnel on old tunnel," Rock and Soil Mechanics, vol. 02, pp. 282-286, 2005.

[16] J. Huang and D. L. Zhang, "Numerical simulation of overburden deformation of subway tunnel," Chinese Journal of Rock Mechanics and Engineering, vol. 12, pp. 2176-2182, 2005.

[17] D. L. Zhang and J. Huang, Journal of China University of Mining and Technology, vol. 05, pp. 88-93, 2004, in Chinese.

[18] Z. L. Zhong, X. R. Liu, F. Yuan et al., "Influence of one-time excavation length of invert on stability of loess multi-arch tunnel," Chinese Journal of Geotechnical Engineering, vol. 03, pp. 462-466, 2008. 